\title{
SR-T100 Gel
}

National Cancer Institute

\section{Source}

National Cancer Institute. SR-T100 Gel. NCI Thesaurus. Code C99460.

A cutaneous gel preparation containing an extract from Solanum incanum with potential antineoplastic activity. SR-T100 gel contains high amounts of the steroidal alkaloid glycoside solamargine. Solamargine is able to upregulate expression of tumor necrosis factor receptors 1 (TNFR1) and 6 (TNFRSF6 or Fas), and their signaling adaptors TNFR1associated death domain, and Fas-associated death domain. In addition, this agent is able to upregulate expression of apoptosis promoter Bax, and suppress the expression of the anti-apoptotic proteins $\mathrm{BCl}-\mathrm{xL}$ and $\mathrm{Bcl}-2$. Altogether, this induces apoptosis in tumor cells and may lead to an inhibition of tumor cell proliferation. 